\title{
Article \\ TmSpz-like Plays a Fundamental Role in Response to E. coli but Not S. aureus or C. albican Infection in Tenebrio molitor via Regulation of Antimicrobial Peptide Production
}

\author{
Ho Am Jang ${ }^{1}$, Bharat Bhusan Patnaik ${ }^{2}{ }^{\mathbb{D}}$, Maryam Ali Mohammadie Kojour ${ }^{1} \mathbb{D}$, Bo Bae Kim ${ }^{1}$, Young Min Bae ${ }^{1}$, \\ Ki Beom Park ${ }^{1}$, Yong Seok Lee ${ }^{3}$ (D), Yong Hun Jo ${ }^{1, *(\mathbb{D})}$ and Yeon Soo Han ${ }^{1, *(\mathbb{D})}$ \\ 1 Department of Applied Biology, Institute of Environmentally-Friendly Agriculture (IEFA), \\ College of Agriculture and Life Sciences, Chonnam National University, Gwangju 61186, Korea; \\ hoamjang@gmail.com (H.A.J.); maryam.alimohammadie@gmail.com (M.A.M.K.); \\ kbb941013@gmail.com (B.B.K.); ugisaka@naver.com (Y.M.B.); misson112@naver.com (K.B.P.) \\ 2 P.G. Department of Biosciences and Biotechnology, Fakir Mohan University, Balasore 756089, India; \\ drbharatbhusan4@gmail.com \\ 3 Department of Biology, College of Natural Sciences, Soonchunhyang University, Asan City 31538, Korea; \\ yslee@sch.ac.kr \\ * Correspondence: yhun1228@jnu.ac.kr (Y.H.J.); hanys@jnu.ac.kr (Y.S.H.)
}

Citation: Jang, H.A.; Patnaik, B.B.; Ali Mohammadie Kojour, M.; Kim, B.B.; Bae, Y.M.; Park, K.B.; Lee, Y.S.; Jo, Y.H.; Han, Y.S. TmSpz-like Plays a Fundamental Role in Response to $E$. coli but Not S. aureus or C. albican Infection in Tenebrio molitor via Regulation of Antimicrobial Peptide Production. Int. J. Mol. Sci. 2021, 22, 10888. https://doi.org/10.3390/ ijms221910888

Academic Editor: Andreas Burkovski

Received: 20 August 2021

Accepted: 4 October 2021

Published: 8 October 2021

Publisher's Note: MDPI stays neutral with regard to jurisdictional claims in published maps and institutional affiliations.

Copyright: (c) 2021 by the authors. Licensee MDPI, Basel, Switzerland. This article is an open access article distributed under the terms and conditions of the Creative Commons Attribution (CC BY) license (https:// creativecommons.org/licenses/by/ $4.0 /)$.

\begin{abstract}
The cystine knot protein Spätzle is a Toll receptor ligand that modulates the intracellular signaling cascade involved in the nuclear factor kappa B (NF- $\mathrm{B})$-mediated regulation of antimicrobial peptide (AMP)-encoding genes. Spätzle-mediated activation of the Toll pathway is critical for the innate immune responses of insects against Gram-positive bacteria and fungi. In this study, the open reading frame (ORF) sequence of Spätzle-like from T. molitor (TmSpz-like) identified from the RNA sequencing dataset was cloned and sequenced. The 885-bp TmSpz-like ORF encoded a polypeptide of 294 amino acid residues. TmSpz-like comprised a cystine knot domain with six conserved cysteine residues that formed three disulfide bonds. Additionally, TmSpz-like exhibited the highest amino acid sequence similarity with T. castaneum Spätzle (TcSpz). In the phylogenetic tree, TmSpz-like and TcSpz were located within a single cluster. The expression of TmSpz-like was upregulated in the Malpighian tubules and gut tissues of T. molitor. Additionally, the expression of TmSpz-like in the whole body and gut of the larvae was upregulated at $24 \mathrm{~h}$ post-E. coli infection. The results of RNA interference experiments revealed that TmSpz-like is critical for the viability of E. coli-infected T. molitor larvae. Eleven AMP-encoding genes were downregulated in the E. coli-infected TmSpz-like knockdown larvae, which suggested that TmSpz-like positively regulated these genes. Additionally, the NF-kB-encoding genes (TmDorX1, TmDorX2, and TmRelish) were downregulated in the E. coliinfected TmSpz-like knockdown larvae. Thus, TmSpz-like plays a critical role in the regulation of AMP production in T. molitor in response to E. coli infection.
\end{abstract}

Keywords: Spätzle; T. molitor; RNA interference; antimicrobial peptide; NF-кB; innate immunity

\section{Introduction}

As invertebrates lack adaptive immunity, their immune responses against pathogens solely depend on innate immunity and physical barriers, such as chitinous shells. The innate immune response is mediated through cell-mediated mechanisms such as encapsulation, nodulation, and phagocytosis or the humoral responses that lead to the production of antimicrobial peptides (AMPs). AMP production, which is the most conserved immune effector mechanism in invertebrates, is induced through the activation of the Toll and IMD signaling cascades. The pattern recognition receptors (PRRs) of the signaling cascades identify the non-self carbohydrate moieties enveloping the pathogens, which are commonly called pathogen-associated molecular patterns (PAMPs). The interaction between PRRs and PAMPs, which can be specific or non-specific, promotes signal transduction through 
the Toll or IMD proteins. The Toll-like receptor (TLR)-nuclear factor kappa B (NF-kB) pathway has been elucidated in Drosophila. In this signaling pathway, the PRRs recognize PAMPs, such as lipopolysaccharides (LPS), peptidoglycans (PGN), and $\beta$-glucans, on the surface of bacteria and fungi and trigger a multi-step proteolytic cascade of serine proteases. Modular serine protease (MSP), which activates the Toll ligand Spätzle (Spz) by processing the inactive pro-Spz, triggers the intracellular signaling cascade mechanism. The binding of Spz to Toll results in the recruitment of the adaptor proteins MyD88, Tube, and Pelle and consequently modulates the responses of the NF- $\mathrm{kB}$ factor Dorsal. The cascade mechanism then activates the transcription factor NF- $\mathrm{KB}$ and upregulates the expression of the effector genes encoding AMPs [1]. The serine protease cascade model has been proposed in Tenebrio molitor [2,3]. Tenebrio GNBP1/PGRP-SA and GNBP3 bind to Lys-type PGN and $\beta-1,3$-glucans, respectively, of bacterial and fungal cell walls, and consequently, in the presence of $\mathrm{Ca}^{2+}$ ions, recruit pro-MSP and process it into activated MSP (aMSP). The aMSP eventually processes pro-Spz to mature Spz along with activated Spz processing enzyme (SPE). SPE itself is recruited by SPE-activating enzyme (SAE). Activated Spz promotes the production of AMPs such as Tenecin 1 and Tenecin 2 through the Toll receptor. Briefly, the TLR-NF-kB pathway in T. molitor is dependent on the cleaved form of Spz. This suggests that Spz proteins have promiscuous roles in the innate immunity of insects against pathogens [4]. Furthermore, TmSpz proteins can function as central immune modulators for biosurfactant-mediated AMP production in T. molitor [5].

In Bombyx mori, the Toll-Spz pathway is critical for eliciting an immune response. Previous studies have reported that BmToll11, BmToll9-1, and five BmSpz genes are upregulated after challenge with Escherichia coli and Staphylococcus aureus. Additionally, only BmSpz2 can interact with BmToll 11 and BmToll9-1 and activate AMP-encoding gene expression [6]. Meanwhile, $B m S p z 4$ is reported to be involved in integument AMP production after challenge with Bacillus and yeast [7]. In Rhynchophorus ferrugineus (red palm weevil), the Spz homolog-mediated Toll-like pathway activation regulates AMP response and maintains gut homeostasis. AMPs such as R. ferrugineus Coleoptericin (RfColeoptericin) and RfCecropin are downregulated in RfSpz knockdown insects, which suggested that their secretion is regulated by RfSpätzle-mediated activation of the Toll signaling pathway [8]. The larvae of T. molitor Spätzle-4 (TmSpz-4) knockdown insects are susceptible to E. coli and C. albicans infections due to the downregulation of AMPs and Toll pathway-related NF- $\mathrm{kB}$ factors (Dorsal X1 and Dorsal X2) [9,10]. Similar results were observed with TmSpz-6 knockdown larvae with positive regulation of AMPs (TmTenecin-2 and TmTenecin-3) after challenge with E. coli and S. aureus [11]. In Drosophila, multiple Toll-Spz combinations activate the antifungal peptide-encoding gene Drosomycin. Drosophila Toll-1 and Toll-7 ectodomains bind to Spz-1, Spz-2, and Spz-5 and activate the expression of Drosomycin [12,13]. Spz homologs and their conserved functions in the Toll pathway have been elucidated in other insects, such as Manduca sexta [14], Antheraea pernyi [15], Anopheles gambiae [16], Aedes aegypti [17], as well as in the shrimps Litopenaeus vannamei $[18,19]$ and Fenneropenaeus chinensis [20].

Previously, we have analyzed the RNA sequencing database of T. molitor to screen various innate immunity-related transcripts [10,21-23]. Nine different TmSpätzle (TmSpz) gene sequences were identified from the database using the T. castaneum Spz sequence (XP_008201191.1) as the query. In this study, a signal peptide region, a cleavage site, and a cysteine knot domain were identified in the novel Spätzle-like from T. molitor (TmSpz-like). The expression of TmSpz-like transcripts was examined during development and in various tissues of the insect using quantitative real-time polymerase chain reaction (qRT-PCR). The expression of TmSpz-like transcripts was upregulated after challenge with microorganisms. RNA interference (RNAi) studies were performed to examine the effect of TmSpz-like knockdown on the viability of the larvae challenged with microorganisms. The findings of this study indicated that the viability of TmSpz-like knockdown larvae infected with E. coli was correlated with the levels of AMP-encoding transcripts. Among the Toll signaling downstream NF-kB factors, the levels of T. molitor Dorsal isoforms (X1 and X2) were downregulated after infection with Gram-negative bacteria, Gram-positive bacteria, and a 
fungus. Only Gram-negative bacteria downregulated the levels of Relish, a downstream transcription factor in IMD signaling. These findings indicate that the TmSpz-like transcript is involved in the innate immunity of T. molitor.

\section{Results}

\subsection{Cloning and Sequence Analysis of TmSpz-like}

The full-length ORF sequence of TmSpz-like (Accession no.: MZ708792) was screened from the RNAseq database using the T. castaneum Spz (TcSpz) sequence (XP_008201191.1) as a query in the tblastn analysis. Molecular cloning analysis confirmed and validated the nucleotide and deduced amino acid sequences. The ORF region of TmSpz-like was $885 \mathrm{bp}$ in length and encoded a protein with 294 amino acid residues. TmSpz-like protein includes a signal peptide region at the $\mathrm{N}$-terminus (cleaved after the first 25 amino acid residues) and a cysteine knot region (amino acid residues 168-269) in the C-terminus containing conserved cysteine residues (residues 175, 215, 222, 236, 265, 266, and 267) that can potentially bind to the Toll receptor (Figure 1). The molecular weight and theoretical isoelectric point of the putative protein were $33.79 \mathrm{kDa}$ and 8.82 , respectively. Pro-Spz is cleaved by SPE. TmSpz-like protein exhibited the characteristics of the Spz family members as evidenced by the presence of cleavage sites.

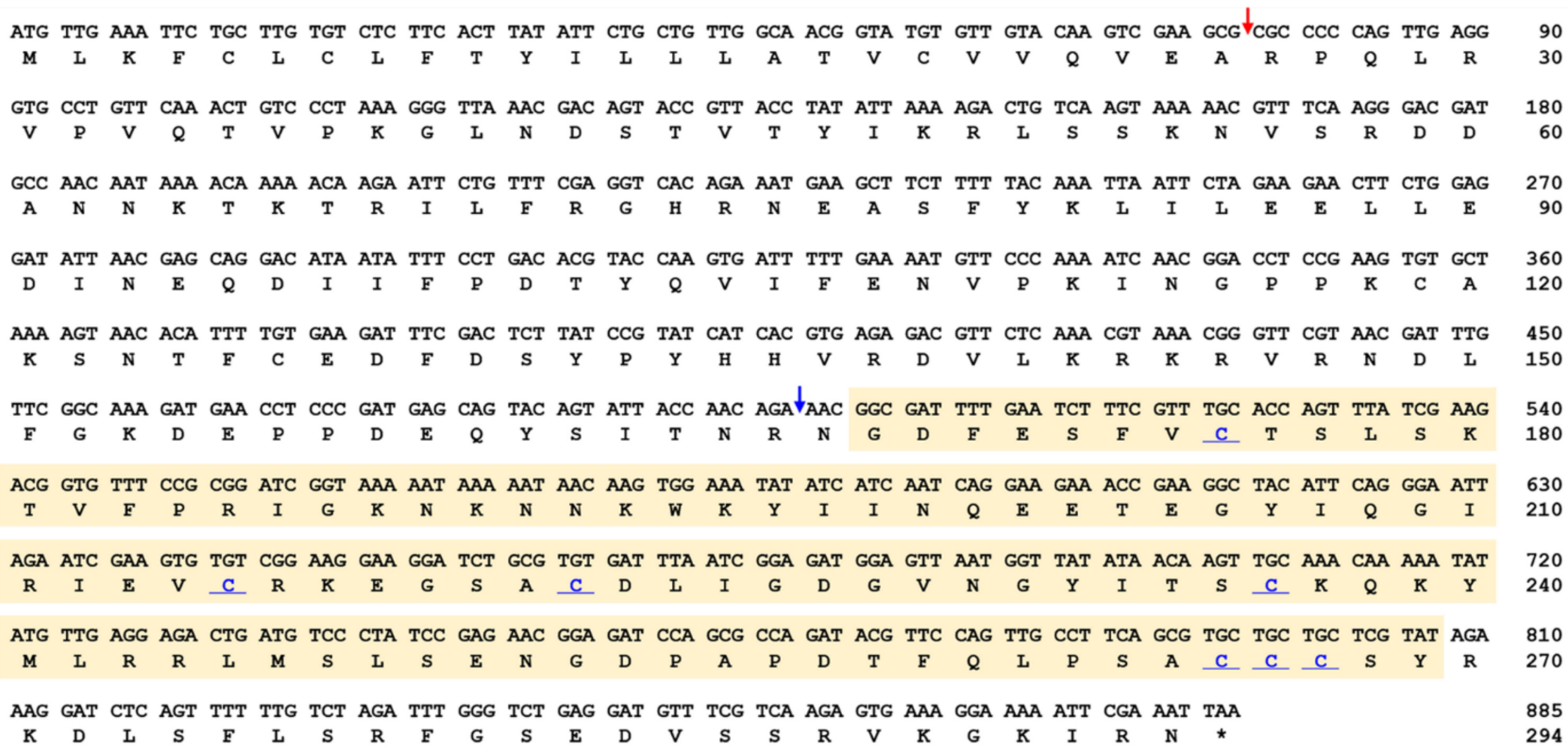

Figure 1. Nucleotide and deduced amino acid sequences of TmSpz-like. TmSpz-like contains an 885 bp open reading frame and encodes a predicted polypeptide of 294 amino acid residues. Domain analysis revealed that TmSpz-like includes a cysteine knot domain (yellow shaded box), a signal peptide region cleaved after 25 amino acid residues (red arrow), and a cleavage site (blue arrow). The conserved cysteine residues of the cysteine knot domain forming three disulfide bridges are shown in blue font. Numbers on the right of each row represent nucleotide and amino acid positions.

\subsection{Phylogenetic Analysis of TmSpz-like}

Multiple sequence alignment was performed to investigate the genetic relationship of TmSpz-like with its homologs. Conserved cysteine residues located in the Spz domain were involved in disulfide bond formation, while one conserved cysteine residue was involved in dimerization. TmSpz-like exhibited the highest amino acid sequence similarity with TcSpz (85\%), followed by Bombus impatiens Spz (BiSpz; 49\%) and Neodiprion lecontei Spz (NlSpz), Cimex lectularius Spz (ClSpz), and Halyomorpha halys Spz (HhSpz) (43\% for all) (Table S1). As shown in Figure 2, TmSpz-like was located closed to its coleopteran counterpart TcSpz in the phylogenetic tree, while BiSpz, ArSpz-like, and NlSpz (Hemipterans) comprised another 
taxon in the same cluster. The Spz sequences belonging to the orders Lepidoptera, Diptera, and Hymenoptera clustered together on separate branches. Spz5-like of the decapod crustacean P. vannamei segregated as an outgroup in the phylogenetic tree. Additionally, the 3D simulation of TmSpz-like (exhibiting 34.31\% identity with the reference crystal structure of Spz cysteine knot homodimer) confirmed the location of two TmSpz-like proteins and determined dimerization and disulfide bond positions of cysteine residues (Figure S1).
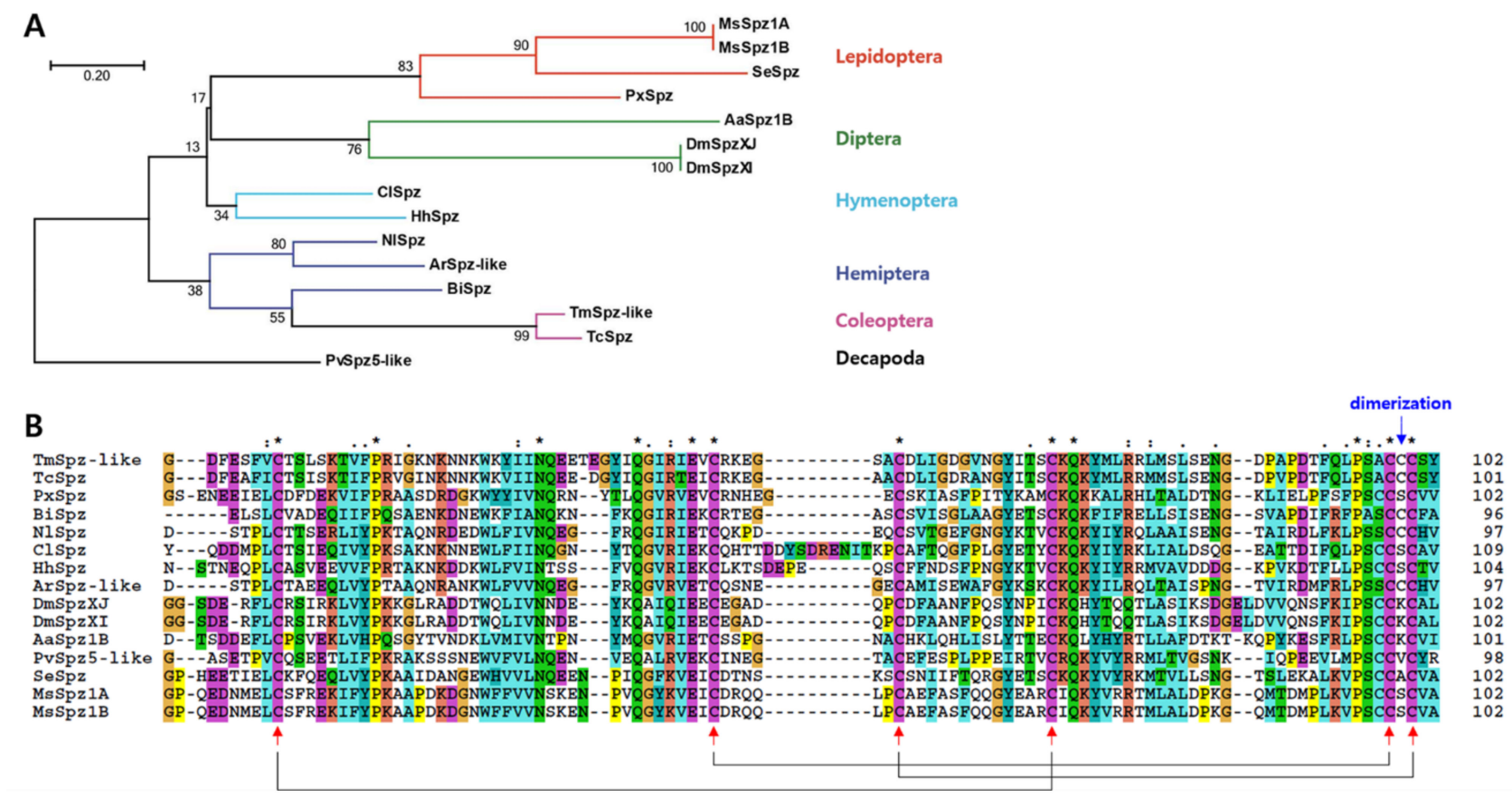

Figure 2. Molecular phylogenetic analysis of TmSpz-like and its homologs in other insects. (A) Maximum likelihood-based phylogenetic tree based on the amino acid sequence of TmSpz-like constructed using the MEGA 7.0 software. The numbers above the branches represent bootstrap values (1000 replications). (B) Multiple alignments of the deduced amino acid sequence of TmSpz-like aligned using Clustal X 2.0.11. Identical and similar sites are identified with asterisks $\left(^{*}\right)$ and dots (: or .), respectively. Arrows represent the phylogenetically conserved cysteine residues forming the disulfide bridges featuring in the cysteine knot domain. The following protein sequences were used in the multiple sequence alignment and phylogenetic analysis: TcSpz, Tribolium castaneum Spätzle (XP_008201191. 1); SeSpz, Spodoptera exigua Spätzle (KAF9408664. 1); PxSpz, Plutella xylostella Spätzle isoform X1 (XP_037962889. 1); MsSpz1A, Manduca sexta Spätzle 1A (ACU68553. 1); MsSpz1B, M. sexta Spätzle 1B (ACU68554. 1); NlSpz, Neodiprion lecontei Spätzle (XP_015518347. 1); ArSpz-like, Athalia rosae Spätzle-like (XP_012257981. 1); BiSpz, Bombus impatiens Spätzle (XP_024228470. 1); ClSpz, Cimex lectularius Spätzle isoform X2 (XP_024082501. 1); HhSpz, Halyomorpha halys Spätzle (KAE8573434. 1); AaSpz1B, Aedes aegypti Spätzle 1B (NP_001350875. 1); DmSpzXJ, Drosophila melanogaster Spätzle isoform J (NP_733192. 1); DmSpzXI, D. melanogaster Spätzle isoform I (NP_733188. 1); PvSpz5-like, Penaeus vannamei Spz5-like (XP_027217999).

\subsection{Developmental and Tissue-Specific Expression Patterns of TmSpz-like}

Developmental and tissue-specific expression patterns of TmSpz-like mRNA were analyzed using qRT-PCR (Figure 3). TmSpz-like mRNA expression was detected in all developmental stages and tissues, with the highest expression detected in the egg and young larval stages (Figure 3A). The expression of TmSpz-like mRNA decreased from the young larval to the pre-pupal stage and subsequently increased on day 1 of the pupal stage and decreased again by day 7. Compared with those in the pupal stages, the TmSpz-like mRNA levels were upregulated in the adult stage. The tissue distributions of TmSpz-like mRNA in T. molitor larva and adults are shown in Figure 3B,C, respectively. qRT-PCR analysis revealed that TmSpz-like mRNA is mostly expressed in the Malpighian tubules 
of the late larvae. The expression of TmSpz-like mRNA in the Malpighian tubules was upregulated by 15 -fold compared with that in other tissues (Figure 3B). In adults, the expression of TmSpz-like mRNA in the gut was upregulated by 20-fold compared with that in other tissues (Figure 3C).
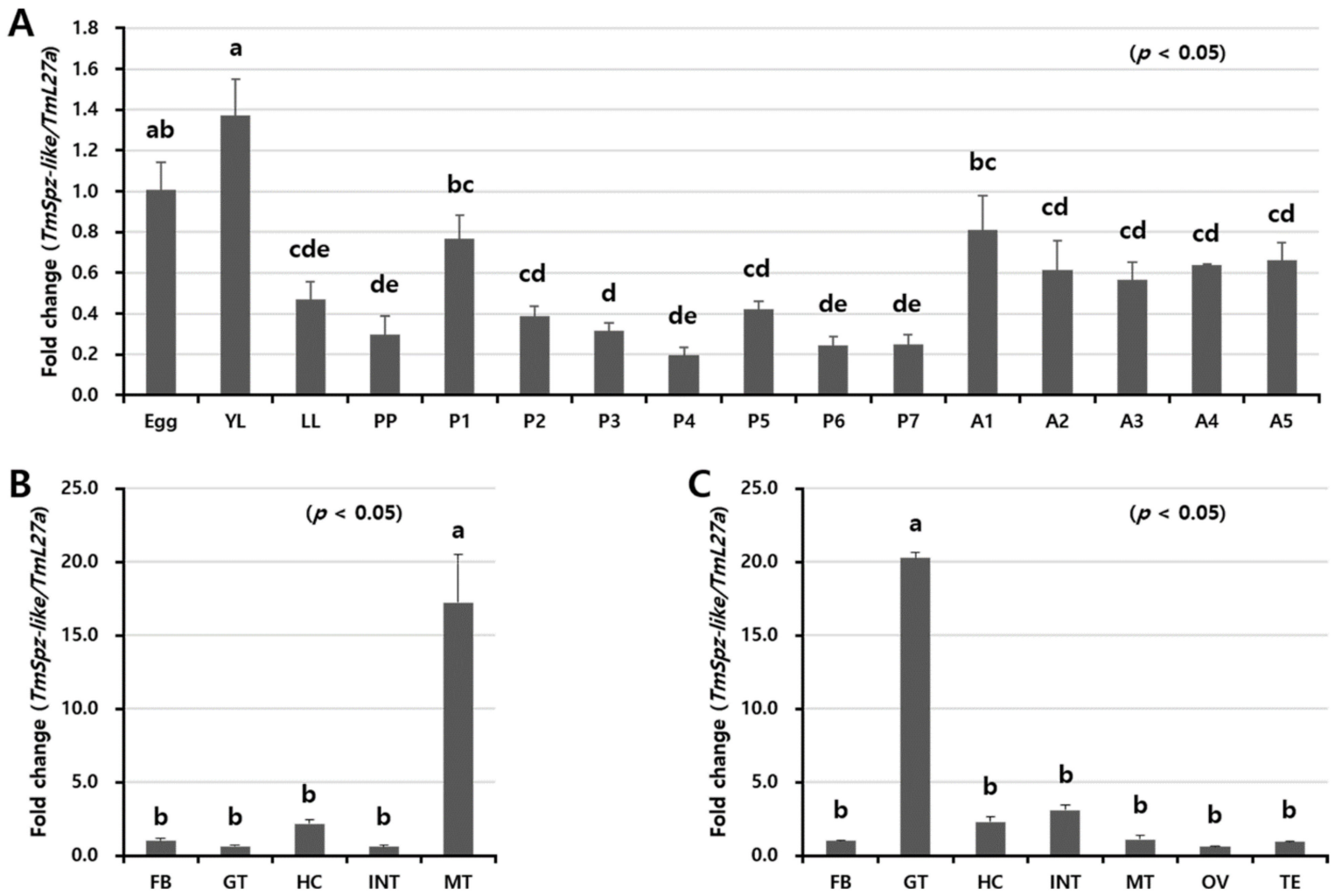

Figure 3. Relative expression levels of TmSpz-like mRNA in different developmental stages and tissues of Tenebrio molitor. (A) Expression levels of TmSpz-like in T. molitor at the egg, the young larval (YL), late larval (LL), pre-pupal (PP), 1-7-day-old pupal (P1-7), and 1-5-day-old adult (A1-5) stages. Tissue distribution of TmSpz-like transcripts in late larvae (B) and five-day-old adults $(\mathrm{C})$ analyzed using quantitative real-time polymerase chain reaction. T. molitor 60S ribosomal protein L27a (TmL27a)-encoding gene was used as an internal control. Fat body (FB), gut (GT), hemocytes (HC), integument (INT), and Malpighian tubules (MT) of late instar larvae and adults, in addition to ovaries (OV) and testes (TE) of adults, were dissected and collected from 20 late larvae and 5-day-old adults for analysis. Vertical bars represent mean \pm standard error from three biological replicates. Data were analyzed using one-way analysis of variance, followed by Tukey's multiple range tests at $95 \%$ confidence level $(p<0.05)$. The graphs indicated by the same letter $(a, b, b c, c, c d, d, d e, e)$ are not significantly different (Tukey's multiple range; $p<0.05$ ).

\subsection{Effect of Microbial Infection on the Expression Patterns of TmSpz-like}

Next, the effect of immune elicitors on the expression of TmSpz-like was examined. The expression levels of TmSpz-like mRNA were examined at 3, 6, 9, 12, and $24 \mathrm{~h}$ in different tissues (gut, fat body, hemocytes, and Malpighian tubules) and the whole body after infection with E. coli, S. aureus, and C. albicans (Figure 4). To account for the effect of injection during the experiment, $\mathrm{PBS}$ ( $\mathrm{pH}$ 7)-injected larvae were used as a negative control. The expression of TmSpz-like mRNA was mostly detected in the whole body at $24 \mathrm{~h}$ post-E. coli injection (Figure 4A). Additionally, the expression of TmSpz-like mRNA was upregulated in the gut (Figure $4 \mathrm{~B}$ ) and fat bodies (Figure $4 \mathrm{C}$ ) at $24 \mathrm{~h}$ post-infection with E. coli, S. aureus, and C. albicans. In the hemocytes, the expression of TmSpz-like mRNA was upregulated at $12 \mathrm{~h}$ post-infection with C. albicans (Figure 4D). The expression of TmSpz-like mRNA was upregulated in the Malpighian tubules at $24 \mathrm{~h}$ post-infection with E. coli and 
S. aureus (Figure 4E). These findings indicated that TmSpz-like mRNA is expressed in all the examined tissues and whole body of T. molitor after infection with various microorganisms.
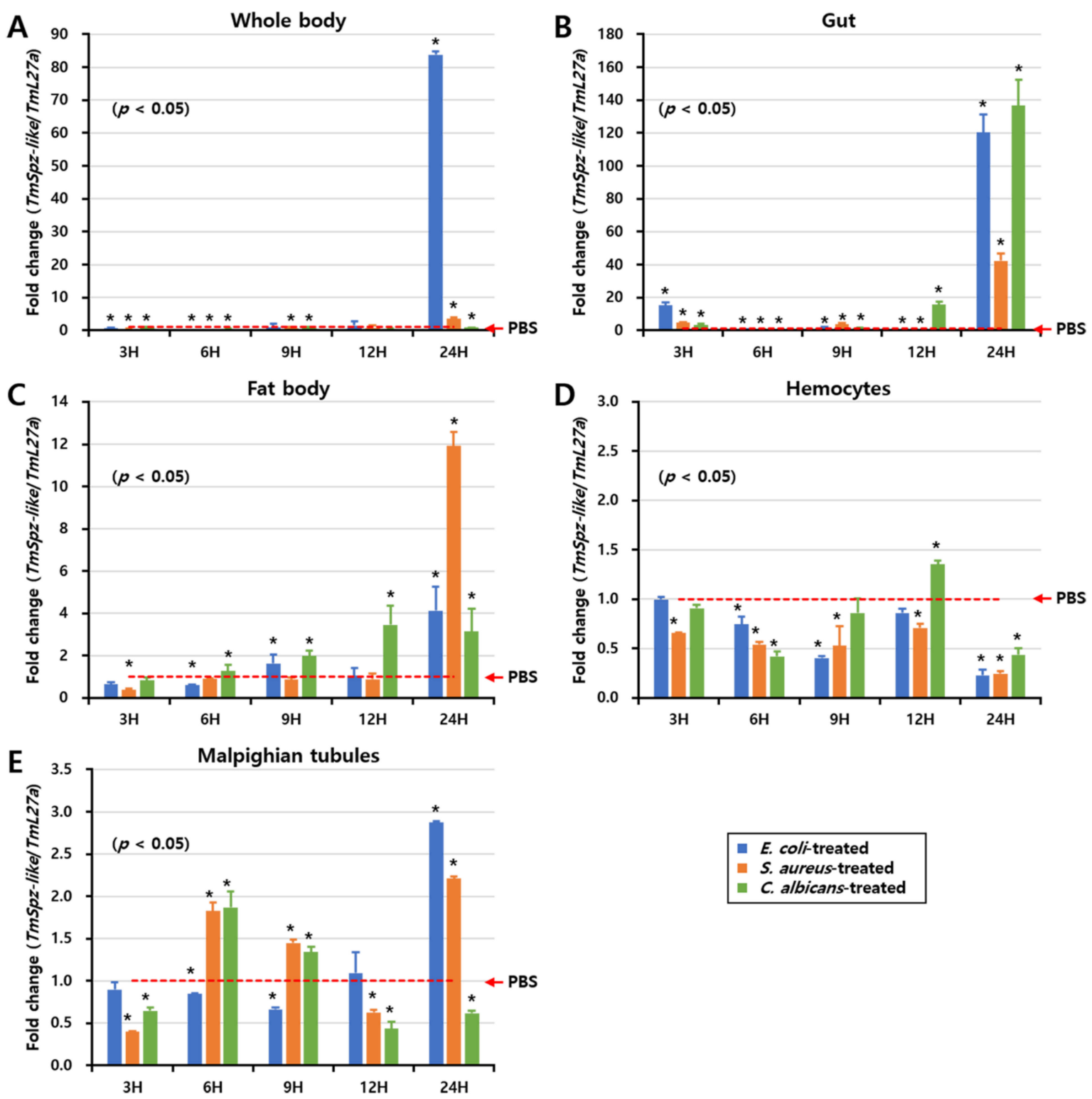

Figure 4. TmSpz-like mRNA expression profiles after microbial challenge. TmSpz-like relative expression levels in the whole body (A), gut (B), fat body (C), hemocytes (D), and Malpighian tubules (E) of larvae infected with Escherichia coli, Staphylococcus aureus, and Candida albicans. The mock control group comprised phosphate-buffered saline-treated larvae. Expression levels of TmSpz-like mRNA in the mock control group were normalized to 1 . Vertical bars represent mean \pm standard error from three biological replicates. Significant differences between the experimental and control groups are indicated by asterisks ( $\left.{ }^{*} p<0.05\right)$.

\subsection{TmSpz-like Knockdown Increased the Mortality of E. coli-Infected T. Molitor Larvae}

To evaluate the role of TmSpz-like in the viability of T. molitor larvae, the dsTmSpz-liketreated larvae were infected with E. coli, S. aureus, and C. albicans (Figure 5). T. molitor larvae treated with enhanced green fluorescent protein (EGFP) dsRNA (dsEGFP) were used as the negative control. qRT-PCR analysis revealed that dsTmSpz-like but not dsEGFP significantly downregulated the expression of the TmSpz-like transcript in the T. molitor larvae. The expression of the TmSpz-like transcript in the dsTmSpz-like-injected larvae decreased 
by approximately $80 \%$ compared with the control group (dsEGFP) at day 4 post-injection (Figure 5A). The viability of TmSpz-like-silenced larvae was measured after infection with E. coli, S. aureus, and C. albicans (Figure 5B-D, respectively) for 10 days. TmSpz-like-knocked down larvae exposed to $E$. coli exhibited less than $60 \%$ viability (Figure $5 \mathrm{~B}$ ). The viability rates significantly decreased at day 8 post-E. coli infection. However, the viability rates of $S$. aureus and C. albicans-infected TmSpz-like-silenced larvae were similar to those of dsEGFP-injected larvae (Figure 5C,D, respectively). This suggested that the knockdown of TmSpz-like increased the mortality of E. coli-infected T. molitor larvae. Thus, E. coli infection affected the viability of the TmSpz knockdown larvae but not S. aureus or C. albicans.
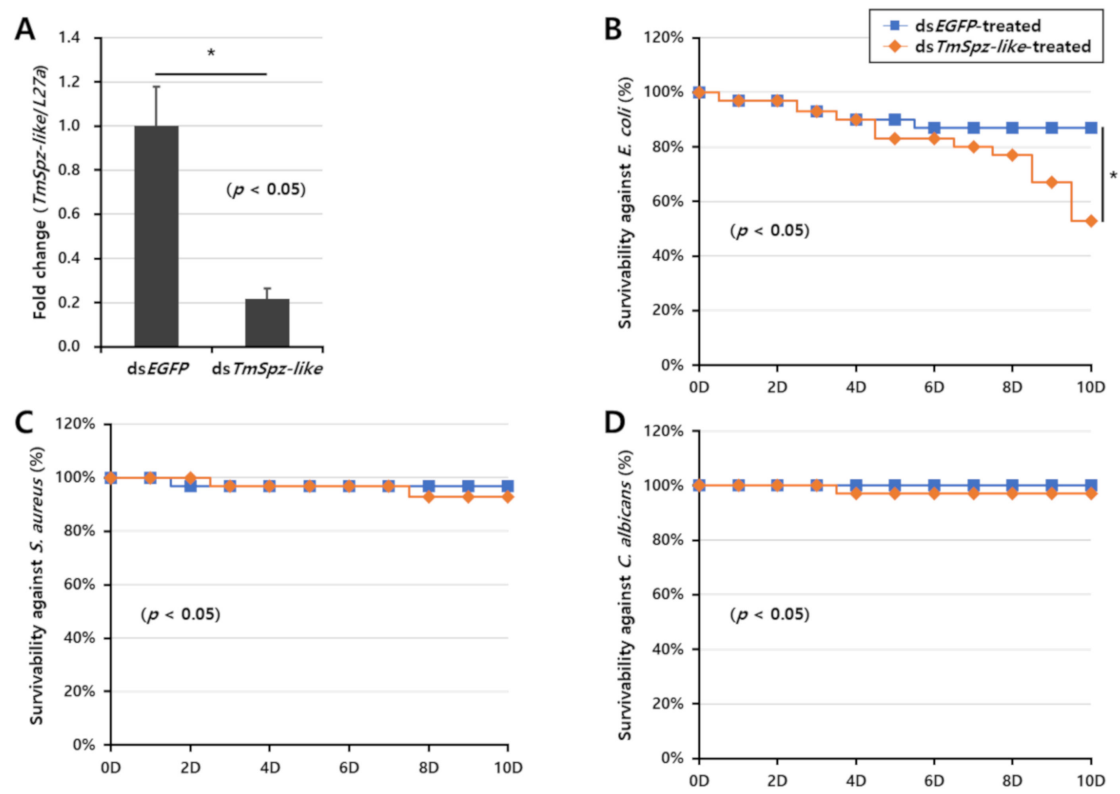

Figure 5. Effect of TmSpz-like knockdown on the viability of Tenebrio molitor larvae. (A) TmSpz-like knockdown efficiency measured using quantitative real-time polymerase chain reaction at day 4 post-injection. Viability of TmSpz-like knockdown larvae after challenge with Escherichia coli (B), Staphylococcus aureus $(\mathbf{C})$, or Candida albicans $(\mathbf{D})(\mathrm{n}=30)$. The negative control comprised dsEGFPinjected larvae. Data are presented as average of three biologically independent replicate experiments. Asterisks indicate significant differences between TmSpz-like-knocked down and dsEGFP-treated groups $(p<0.05)$. Survival rates were analyzed based on the Kaplan-Meier plots (log-rank chi-square test; * $p<0.05)$.

\subsection{Effects of TmSpz-like Knockdown on the Expression of AMPs and NF- $\mathrm{B} B$}

The findings of this study indicated that TmSpz-like plays an important role in the defense response against E. coli. TmSpz-like regulates AMP expression through the Toll signaling pathway. Thus, the expression levels of 15 different AMP-encoding genes in the whole body of TmSpz-like knockdown T. molitor larvae were examined at $6 \mathrm{~h}$ post-infection with E. coli, S. aureus, and C. albicans (Figure 6). Of the 15 AMP genes examined, the following 11 genes were significantly downregulated in the E. coli-infected TmSpz-like knockdown T. molitor larvae: TmTene1, TmTene2, TmTene4, TmDef, TmDef-like, TmColeA, TmColeB, TmColeC, TmAtt1a, TmAtt1b, and TmAtt2. The expression levels of TmTene3, TmCec2, TmTLP1, and TmTLP2 were non-significantly different between the E. coli-infected and control TmSpz-like knockdown T. molitor larvae. Meanwhile, the expression levels of the following 13 AMP-encoding mRNAs were downregulated in the S. aureus-infected TmSpzlike knockdown T. molitor larvae: TmTene1, TmTene2, TmTene4, TmDef, TmDef-like, TmCec2, TmColeA, TmColeB, TmColeC, TmAtt1a, TmAtt1b, TmAtt2, and TmTLP1. The mRNA levels of TmTene1, TmTene2, TmTene4, TmDef, TmDef-like, TmCec2, TmColeA, TmColeB, TmColeC, TmAtt1a,TmAtt1b, TmAtt2, TmTLP1, and TmTLP2 were slightly downregulated in the C. albicans-infected TmSpz-like knockdown T. molitor larvae (Figure 6). 

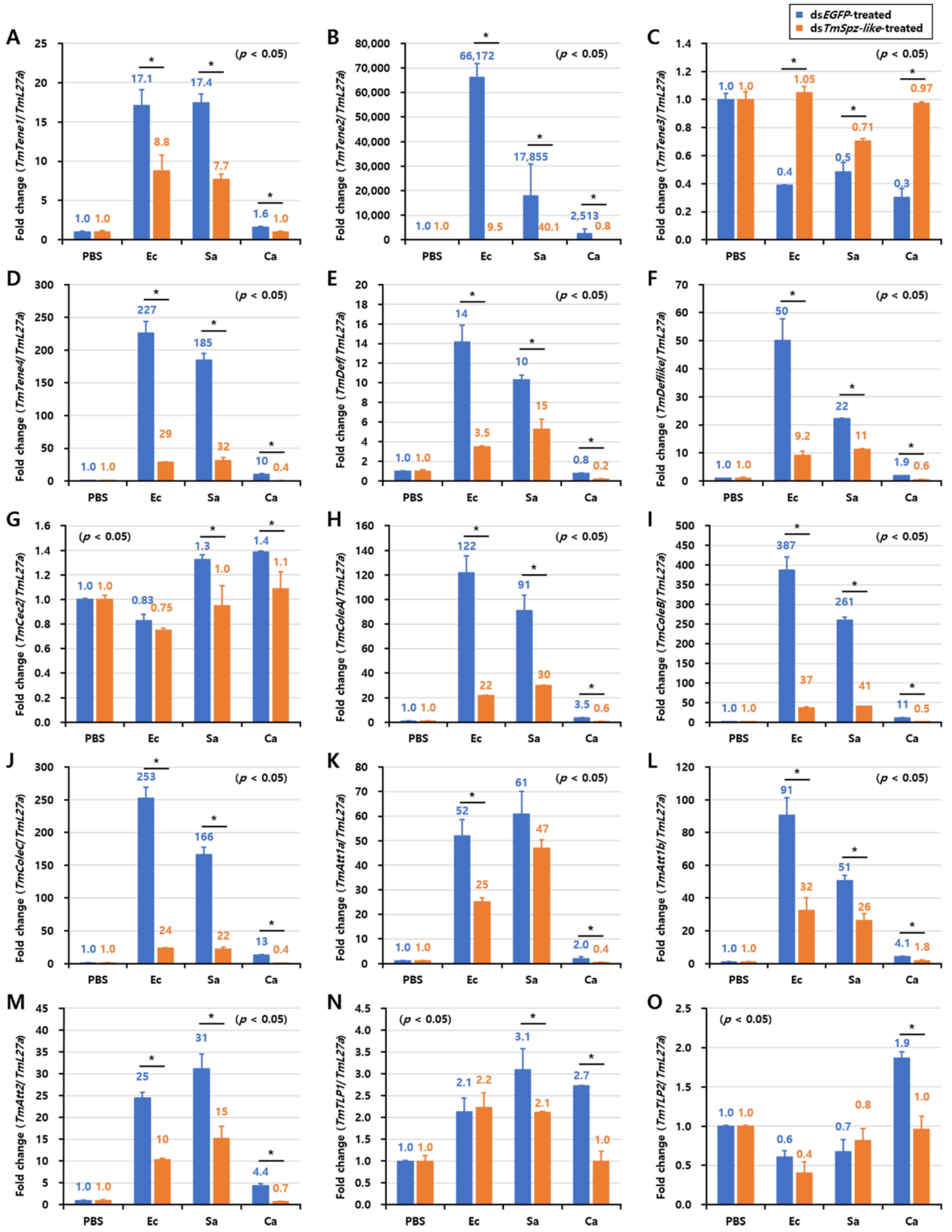

Figure 6. Antimicrobial peptide (AMP)-encoding mRNA expression patterns in whole body of TmSpz-like knockdown larvae in response to Escherichia coli, Staphylococcus aureus, and Candida albicans infections. Phosphate-buffered saline (PBS) was injected as a control at day 4 post-TmSpz-like knockdown. At $6 \mathrm{~h}$ post-microbial challenge, the expression levels of AMP-encoding genes, including TmTene1 (A), TmTene2 (B), TmTene3 (C), TmTene4 (D), TmDef (E), TmDef-like (F),

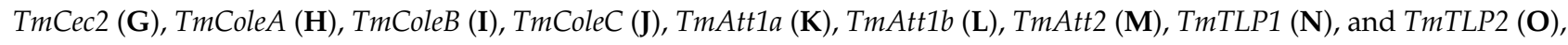
were measured using quantitative real-time polymerase chain reaction. dsEGFP was injected as a negative control. TmL27a expression was measured as an internal control. The number above the bars represents the AMP transcriptional levels. The experiments were performed in biological triplicates. Asterisks indicate significant differences between dsTmSpz-like- and dsEGFP-injected groups (Student's $t$-test; ${ }^{*} p<0.05$ ). 
To narrow down the effect of TmSpz-like on AMP expression, the expression levels of Toll and IMD NF-kB-related factors (TmDorX1, TmDorX2, and TmRelish) were measured under the same conditions (Figure 7). The mRNA expression levels of TmDorX1, TmDorX2, and TmRelish were downregulated in the E. coli-infected TmSpz-like knockdown T. molitor larvae. Similarly, the mRNA expression levels of TmDorX1 and TmDorX2 were downregulated in the S. aureus-infected and C. albicans-infected TmSpz-like knockdown T. molitor larvae. Furthermore, the mRNA levels of TmRelish were downregulated in the E. coli-infected TmSpz-like knockdown T. molitor larvae but not in the S. aureus-infected and C. albicans-infected TmSpz-like knockdown T. molitor larvae.

A
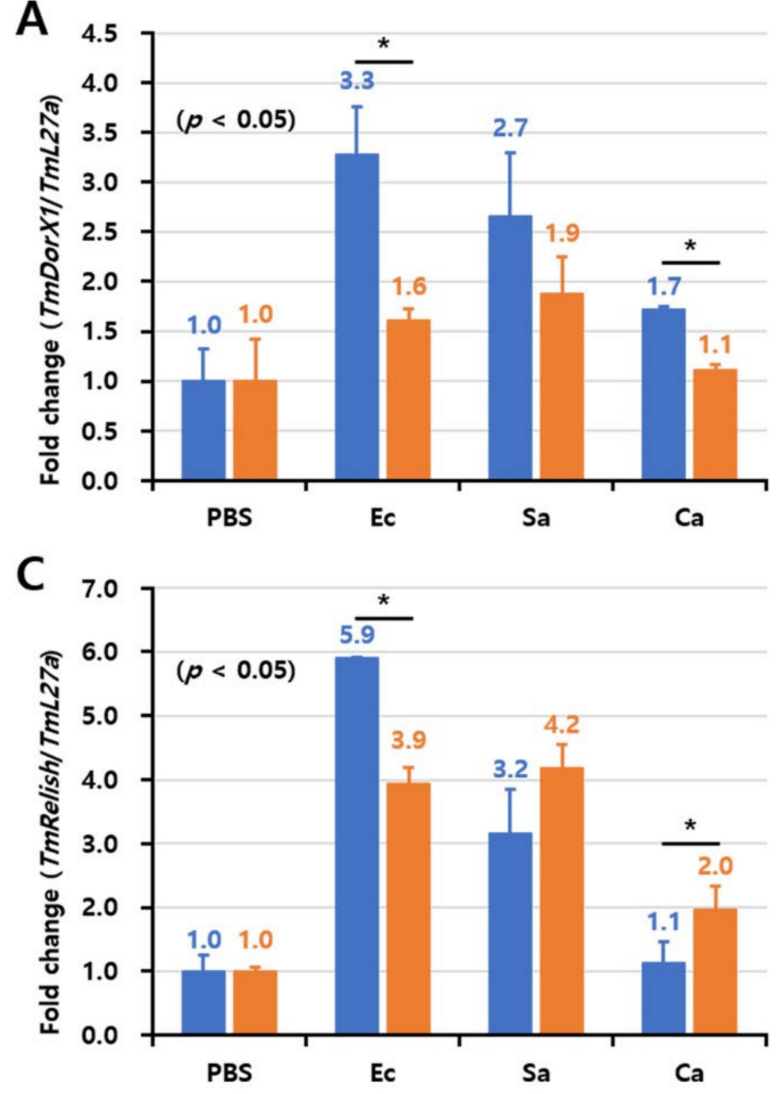

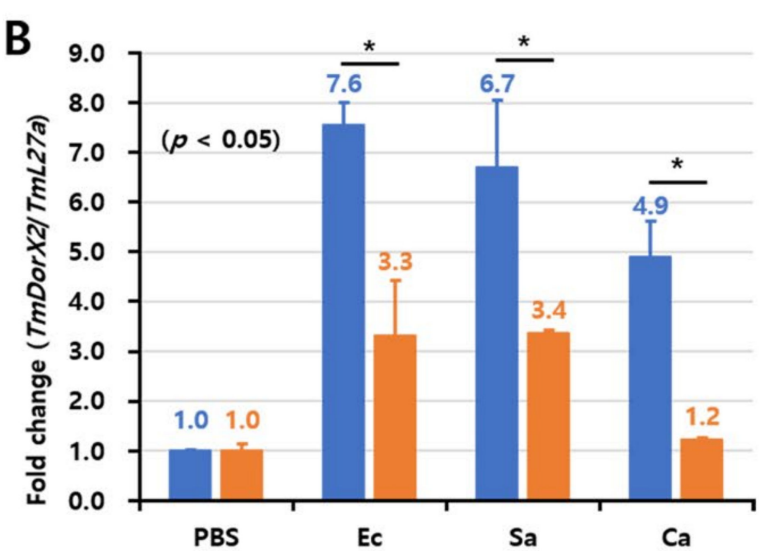

PBS
dsEGFP-treated

- dsTmSpz-like-treated

Figure 7. Effect of TmSpz-like knockdown on the expression of nuclear factor kappa B (NF- $\mathrm{B}$ )-encoding genes after challenge with Escherichia coli, Staphylococcus aureus, and Candida albicans. mRNA expression levels of TmDorX1 (A), TmDorX2 (B), and TmRelish $(\mathbf{C})$ were investigated using quantitative real-time polymerase chain reaction. The negative control comprised dsEGFP-injected larvae. TmL27a expression was assessed as an internal control. All experiments were performed in triplicate. Asterisks indicate significant differences in NF-kB-encoding gene expression between the dsTmSpz-like and dsEGFP-injected groups (Student's $t$-test; * $p<0.05$ ).

These findings indicate that TmSpz-like regulates the expression of 11 AMPs in response to E. coli infection in T. molitor larvae. The roles of NF-kB-related transcription factors such as Dorsal isoforms or Relish in the immune response to pathogen infection are unclear (Figure 8). 
Which Pathogens?

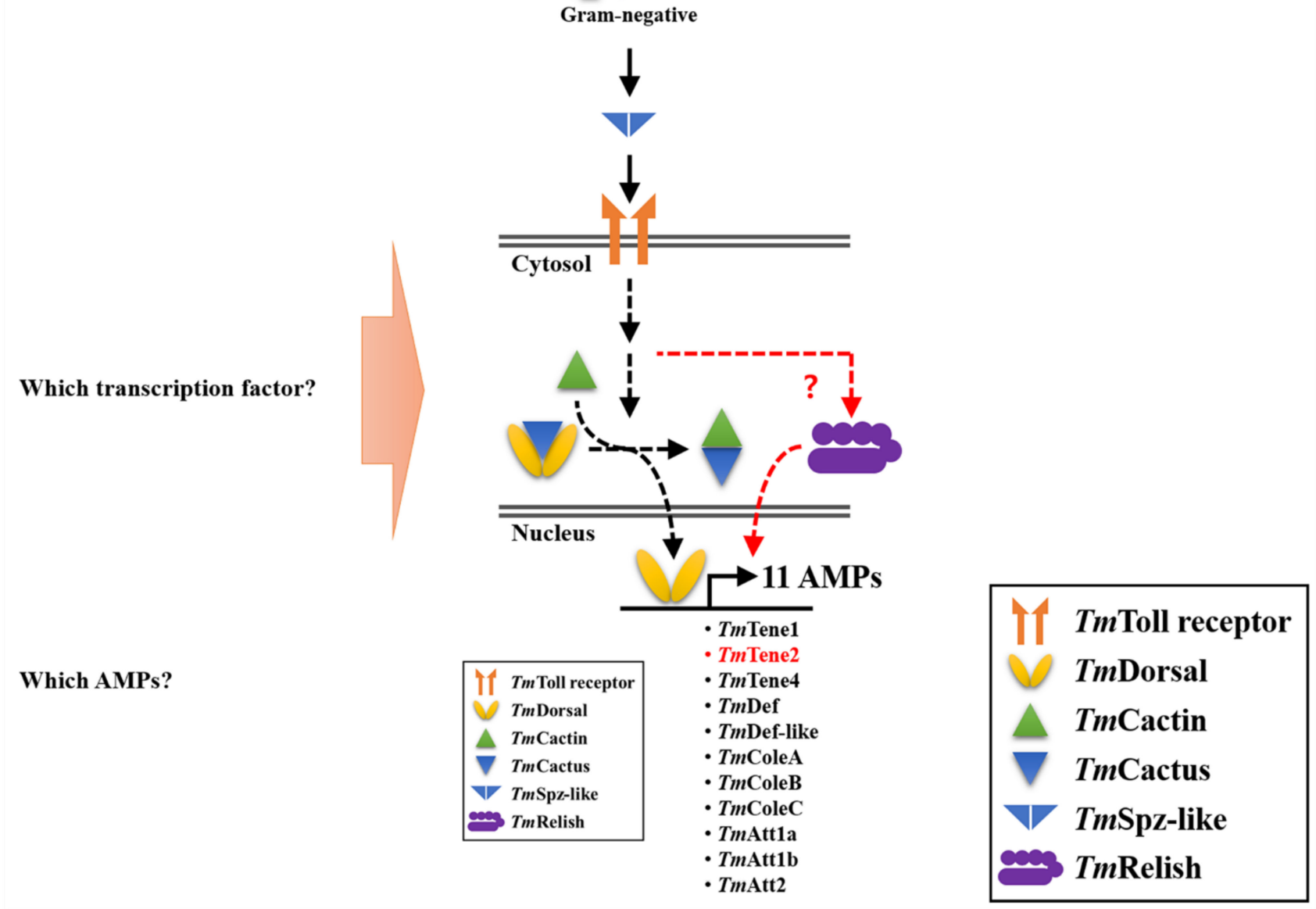

Figure 8. An illustrative summary of the humoral immune pathway positively regulated by TmSpz-like in Escherichia coli-infected Tenebrio molitor. Eleven antimicrobial peptide (AMP)-encoding genes were regulated by TmSpz-like, which indicated that TmSpz-like is required for the survival of the E. coli-infected host.

\section{Discussion}

The Toll receptor ligand Spz belongs to the family of proteins involved in the signaling pathway required for dorso-ventral patterning in the early embryo and antifungal response in the larvae and adults of Drosophila [24]. The homologs of Spz encode proteins with cysteine knot domains. The $S p z$ gene family was derived from ancient gene duplication events, and the gene products activate the Toll receptor ligands. In Drosophila, Spz-4 and Spz-6, which are expressed in the late embryo, are involved in the antifungal response along with Toll 5 and development, respectively $[25,26]$. In T. molitor, Spz-4 is involved in the transcriptional regulation of AMPs, which modulate the humoral immune response against E. coli and C. albicans [9], whereas T. molitor Spz-6 protects the larvae against E. coli and S. aureus by positively regulating the expression of the AMPs Tenecin- 2 and Tenecin-3 [11]. In this study, the full-length ORF sequence of TmSpz-like was identified and characterized using a molecular informatics approach. The cysteine motif domain of $T m S p z-l i k e$ comprises conserved cysteine residues involved in disulfide bond formation, while one cysteine was involved in dimerization. A cysteine knot domain at the C-terminus, a cleavage region, and a signal peptide region has been identified in TmSpz- 4 and TmSpz$6[9,11]$. Spz isoforms identified from the crustacean L. vannamei contain the signal peptide region and a cysteine knot region for Toll binding [18]. Serine protease mediates the cleavage of pro-Spz to generate activated Spz. The Spz cysteine-rich domains, which bind to the concave surface of the Toll leucine-rich repeat region, are involved in intracellular 
signal transduction. The activation of the Toll receptor by Spz mediates nuclear localization of the NF-kB/Rel transcription factor Dorsal, which promotes the transcription of AMPs and development-associated differentiation genes $[27,28]$. To examine the evolutionary relationships of TmSpz-like with its homologs in other insects, phylogenetic analysis of the TmSpz-like sequence was performed. TmSpz-like exhibited the highest amino acid sequence similarity with the coleopteran TcSpz, followed by the Hemipteran BiSpz, ArSpzlike, and NISpz. Previous studies have reported that TmSpz-4 and TmSpz-6 exhibited the least sequence similarity with $T c S p z[9,11]$.

In contrast to those of TmSpz-4 and TmSpz-6, mRNA levels of TmSpz-like were upregulated in the egg, early larvae, and adult stages of T. molitor development. Additionally, the tissue distribution of TmSpz-like in the larval (maximum in the Malpighian tubules) and adult tissues (maximum in the gut) was different from that of TmSpz-4 and TmSpz-6. The expression of $S p z$ is regulated by hormonal changes during development, and pupal stages are associated with enhanced hormonal changes [29]. Hence, TmSpz-like expression is negatively correlated with hormonal changes. The upregulated expression of the TmSpz-like transcript during the egg stage may also be related to its functions, especially ventral-specific differentiation, during embryonic development, whereas the upregulated expression of TmSpz-like mRNA in the Malpighian tubules may be because the tissue does not undergo ecdysone-induced destruction as other larval tissues. In a non-infection model, AMPs rapidly respond to ecdysone in the tissue [30,31]. Furthermore, the expression of the Spz homolog was upregulated in the gut and fat body of the red palm weevil $R$. ferrugineus after systemic and oral inoculation of S. aureus, E. coli, and Beauveria bassiana, which suggested the role of the homolog Spz in systemic and gut-specific immune responses against infections [8]. TmSpz-4 mRNA expression peaked at 9 and $24 \mathrm{~h}$ post-injection with E. coli and $S$. aureus, which confirmed the gut-specific immunity [9]. In this study, TmSpz-like mRNA exhibited the highest expression in the gut at $24 \mathrm{~h}$ post-inoculation with E. coli and C. albicans. E. coli was the only pathogen to promote the expression of TmSpz-like in the whole body of T. molitor larvae. The expression of TmSpz-like marginally increased in other tissues of T. molitor, which indicated that E. coli promoted Spz expression in T. molitor. Similar to TmSpz-4 and TmSpz-6, TmSpz-like gene expression was upregulated after E. coli exposure [9,11]. Thus, E. coli (Gram-negative bacteria) can activate Spz and promote its binding to the Toll receptor in T. molitor and subsequently modulate the NF- $\kappa \mathrm{B}$-mediated transcriptional regulation of AMP-encoding genes. The silencing of TmSpz-like transcripts increased the mortality in T. molitor larvae after E. coli infection but not after $S$. aureus or C. albicans infection. This suggests that TmSpz-like is required for protection against E. coli infection in the larvae. Nevertheless, the knockdown of TmSpz-like did not result in cross-silencing effects on TmSpz-4 and TmSpz-6. The sensitivity of T. molitor larvae with downregulated expression of TmSpz-like, TmSpz-4, and TmSpz-6 to E. coli infections may be related to cross-talk between the Toll and IMD pathways. E. coli induces the activation of Spz in T. molitor larvae, suggesting that polymeric DAP-type PGN forms a complex with Tenebrio PGRP-SA to activate the Toll receptor ligand Spz [4,32]. The induction of the Toll pathway in Drosophila and T. molitor depends on the binding of Spz to Toll. The crustacean Toll directly binds to Gram-positive and Gram-negative bacteria and promotes Dorsal-mediated AMP expression [33]. In M. sexta, Gram-negative and Gram-positive bacteria activate a clip-domain proteinase proHP6 in the plasma. Subsequently, proHP6 activates proHP8, which activates Spz1 to bind to Toll and mediate the broad response to infection [34].

The knockdown of TmSpz-like significantly suppressed the expression of TmTene1, TmTene2, TmTene4, TmDef, TmDef-like, TmColeA, TmColeB, TmColeC, TmAtt1a, TmAtt1b, and TmAtt2 in the E. coli-infected T. molitor larvae. The viability of E. coli-infected TmSpzlike knockdown T. molitor larvae may have decreased due to the downregulation of the AMP-encoding genes. These AMPs are reported to exert growth-inhibitory activity against E. coli [35-40]. TmTenecin3, an antifungal peptide, and TmThaumatin-like proteins are majorly induced in plant systems due to stress and other pathogenic insults [41,42]. These 
peptides were not downregulated in TmSpz-like knockdown larvae after infection with E. coli. The expression levels of TmTene1, TmTene2, TmTene4, TmDef2, TmCole1, TmCole2, TmAtt1a, TmAtt1b, and TmAtta2 were downregulated in the TmIMD knockdown larvae after E. coli infection [22]. This indicates that the same AMPs are regulated under IMD and Toll pathways after E. coli infection. In the mosquito A. aegypti Aag2 cells, the AMP Gambicin is regulated by the combination of Toll, IMD, and JAK-STAT pathways [43]. To examine the regulation of AMP production and delineate the roles of NF- $\mathrm{kB}$-mediated regulation of these AMPs, the expression of Dorsal isoforms (X1 and X2) and Relish in TmSpz-like knockdown larvae was examined after pathogenic challenges. The mRNA expression levels of TmDorX1, TmDorX2, and TmRelish were downregulated in E. coliinfected TmSpz-like knockdown larvae, which indicated that all NF- $\mathrm{kB}$ factors may regulate the 11 AMPs [44]. We speculated that TmSpz-like promotes the viability of E. coli-infected T. molitor by regulating the expression of 11 AMP-encoding genes. In addition to the Toll pathway-mediated NF- $\mathrm{kB}$ factors, TmDorX1 and X2 and IMD-pathway-mediated TmRelish may be involved in promoting viability. TmRelish-mediated regulation of the 11 AMPs through the Toll pathway activated by TmSpz-like must be elucidated.

\section{Conclusions}

In this study, we functionally characterized the TmSpz-like homolog from T. molitor. Previously, we had characterized the antifungal and antibacterial activities of TmSpz-4 and TmSpz-6. TmSpz-like exhibited the typical cysteine knot region with conserved cysteine residues. The expression of TmSpz-like mRNA was upregulated in the egg, early larvae, and adults. This was in contrast to the upregulated expression of TmSpz-4 and TmSpz-6 in the pupal stage. E. coli significantly decreased the viability of TmSpz-like knockdown larvae, which can be attributed to the downregulation of 11 AMP genes. Furthermore, the transcription factors involved in the Toll (TmDorX1 and X2) and the IMD (TmRelish) pathways were downregulated in E. coli-infected TmSpz-like knockdown larvae.

\section{Materials and Methods}

\subsection{Insect Rearing}

Mealworm beetles (T. molitor) were reared at $27 \pm 1{ }^{\circ} \mathrm{C}$ and $60 \% \pm 5 \%$ relative humidity in an environmental chamber under dark conditions. The reared larvae were fed with an artificial diet containing $170 \mathrm{~g}$ wheat flour, $20 \mathrm{~g}$ roasted soy flour, $10 \mathrm{~g}$ protein, $100 \mathrm{~g}$ wheat bran, $0.5 \mathrm{~g}$ sorbic acid, $0.5 \mathrm{~mL}$ propionic acid, and $0.5 \mathrm{~g}$ chloramphenicol in $200 \mathrm{~mL}$ of distilled water. Healthy tenth to twelfth instar larvae were fed with the dietary mixture, which was pre-autoclaved at $121{ }^{\circ} \mathrm{C}$ for $15 \mathrm{~min}$.

\subsection{Microorganisms}

The Gram-negative bacterium Escherichia coli K12, the Gram-positive bacterium Staphylococcus aureus RN4220, and the fungus Candida albicans AUMC 13529 were used for the immune challenge experiments. E. coli and S. aureus were cultured overnight in Luria-Bertani broth at $37^{\circ} \mathrm{C}$, while C. albicans was cultured in Sabouraud dextrose broth. The microorganisms were harvested, washed twice with phosphate-buffered saline (PBS; pH 7.0), and centrifuged at $5000 \mathrm{~g}$ for $15 \mathrm{~min}$. Next, the samples were suspended in PBS, and the optical density of the suspension at $600 \mathrm{~nm}$ was measured using a spectrophotometer (Eppendorf, Germany). The density of E. coli and S. aureus was adjusted to $1 \times 10^{6}$ cells $/ \mu \mathrm{L}$, while that of $C$. albicans was adjusted to $5 \times 10^{4}$ cells $/ \mu \mathrm{L}$ for immune challenge experiments.

\subsection{In Silico Identification and Cloning of the Full-Length TmSpz-Like cDNA}

The TmSpz-like sequence was identified from the T. molitor RNAseq (unpublished) and expressed sequence tag databases. Local-tblastn analysis was performed using the amino acid sequence of T. castaneum Spz (XP_008201191.1) as a query. The deduced amino acid sequence of TmSpz was analyzed using the BLASTx and BLASTp algorithms at the National Center for Biotechnology Information (https:/ /blast.ncbi.nlm.nih.gov / Blast.cgi) 
with nr database. The full-length target open reading frame (ORF) regions were amplified using an AccuPower Pfu PreMix (Bioneer, Daejeon, South Korea) and a MyGenie 96 thermal block (Bioneer, Daejeon, South Korea) with gene-specific primers designed using Primer 3.0 software (http:/ / bioinfo.ut.ee/primer3-0.4.0/) (Table 1). The PCR-purified products were cloned into the T-blunt vector cloning system (Solgent Company, Daejeon, Korea). The recombinant vector was transformed into E. coli DH5 $\alpha$ cells and sequenced using M13 primers. The full-length ORF sequence was validated after sequencing.

Table 1. Primers used in this study.

\begin{tabular}{|c|c|}
\hline Name & Primer Sequences $\left(5^{\prime}-3^{\prime}\right)$ \\
\hline TmSpz-like-ORF-Fw & CGTTTTCAGCGGCTAATTGT \\
\hline TmSpz-like-ORF-Rv & САТААТTСССТTТТСССААТTT \\
\hline \multirow{2}{*}{ TmSpz-like-T7-Fw } & TAATACGACTCACTATAGGGT \\
\hline & $\overline{\text { ATGTTCCCAAAATCAACGGA }}$ \\
\hline \multirow{2}{*}{ TmSpz-like-T7-Rv } & TAATACGACTCACTATAGGGT \\
\hline & $\overline{\text { AATCACACGCAGATCCTTCC }}$ \\
\hline \multirow{2}{*}{ EGFP-T7-Fw } & TAATACGACTCACTATAGGGT \\
\hline & $\overline{\text { CGTAAACGGCCACAAGTTC }}$ \\
\hline \multirow{2}{*}{ EGFP-T7-Rv } & TAATACGACTCACTATAGGGT \\
\hline & TGCTCAGGTAGTGTTGTCG \\
\hline TmSpz-like-qPCR-Fw & CAGTTGAGGGTGCCTGTTCA \\
\hline TmSpz-like-qPCR-Rv & TTGTTGGCATCGTCCCTTGA \\
\hline TmL27a-qPCR-Fw & TCATCCTGAAGGCAAAGCTCCAGT \\
\hline TmL27a-qPCR-Rv & AGGTTGGTTAGGCAGGCACCTTTA \\
\hline TmTenecin-1-qPCR-Fw & CAGCTGAAGAAATCGAACAAGG \\
\hline TmTenecin-1-qPCR-Rv & CAGACCCTCTTTCCGTTACAGT \\
\hline TmTenecin-2-qPCR-Fw & CAGCAAAACGGAGGATGGTC \\
\hline TmTenecin-2-qPCR-Rv & CGTTGAAATCGTGATCTTGTCC \\
\hline TmTenecin-3-qPCR-Fw & GATTTGCTTGATTCTGGTGGTC \\
\hline TmTenecin-3-qPCR-Rv & CTGATGGCCTCCTAAATGTCC \\
\hline TmTenecin-4-qPCR-Fw & GGACATTGAAGATCCAGGAAAG \\
\hline TmTenecin-4-qPCR-Rv & CGGTGTTCCTTATGTAGAGCTG \\
\hline TmDefensin-Fw & AAATCGAACAAGGCCAACAC \\
\hline TmDefensin-Rv & GCAAATGCAGACССТCTTTC \\
\hline TmDefensin-like-Fw & GCGATGCCTCATGAAGATGTAG \\
\hline TmDefensin-like-Rv & CCAATGCAAACACATTCGTC \\
\hline TmColeoptericin-A-qPCR-Fw & GGACAGAATGGTGGATGGTC \\
\hline TmColeoptericin-A-qPCR-Rv & СТССАACATTCCAGGTAGGC \\
\hline TmColeoptericin-B-qPCR-Fw & CAGCTGTTGCCCACAAGTG \\
\hline TmColeoptericin-B-qPCR-Rv & CTCAACGTTGGTCCTGGTGT \\
\hline TmColeoptericin-C-qPCR-Fw & GGACGGTTCTGATCTTCTTGAT \\
\hline TmColeoptericin-C-qPCR-Rv & CAGCTGTTTGTTTGTTCTCGTC \\
\hline TmAttacin-1a-Fw & GAAACGAAATGGAAGGTGGA \\
\hline TmAttacin-1a-Rv & TGCTTCGGCAGACAATACAG \\
\hline TmAttacin-1b-Fw & GAGCTGTGAATGCAGGACAA \\
\hline TmAttacin-1b-Rv & СССТСТGATGAAAССТССАA \\
\hline TmAttacin-2-Fw & AACTGGGATATTCGCACGTC \\
\hline TmAttacin-2-Rv & CCCTCCGAAATGTCTGTTGT \\
\hline TmCecropin-2-Fw & TACTAGCAGCGCCAAAACCT \\
\hline TmCecropin-2-Rv & CTGGAACATTAGGCGGAGAA \\
\hline
\end{tabular}


Table 1. Cont.

\begin{tabular}{|c|c|}
\hline Name & Primer Sequences $\left(5^{\prime}-3^{\prime}\right)$ \\
\hline TmThaumatin-like protein-1-Fw & CTCAAAGGACACGCAGGACT \\
\hline TmThaumatin-like protein-1-Rv & ACTTTGAGCTTCTCGGGACA \\
\hline TmThaumatin-like protein-2-Fw & CCGTCTGGCTAGGAGTTCTG \\
\hline TmThaumatin-like protein-2-Rv & АСТССТCCAGCTCCGTTACA \\
\hline TmDorX1_qPCR_Fw & AGCGTTGAGGTTTCGGTATG \\
\hline TmDorX1_qPCR_Rv & TCTTTGGTGACGCAAGACAC \\
\hline TmDorX2_qPCR_Fw & ACACCCCCGAAATCACAAAC \\
\hline TmDorX2_qPCR_Rv & TTTCAGAGCGCCAGGTTTTG \\
\hline TmRelish_qPCR_Fw & AGCGTCAAGTTGGAGCAGAT \\
\hline TmRelish_qPCR_Rv & GTCCGGACCTCAAGTGT \\
\hline
\end{tabular}

Underline indicates $\mathrm{T} 7$ promotor sequences.

\subsection{Domain and Phylogenetic Analyses}

The domain architecture of the protein sequences was retrieved using the InterProScan domain analysis (https://www.ebi.ac.uk/interpro/search/sequence-search) and BLASTp programs. The signal peptide was predicted using the SignalP 5.0 server (http:/ / www.cbs. dtu.dk/services/SignalP/). Additionally, the three-dimensional (3D) structure of TmSpzlike was predicted using the SWISS-MODEL server (https:/ / swissmodel.expasy.org).

The ClustalX v. 2.1 [45]-based multiple sequence alignment profile was used to analyze the genetic relatedness among Spz-like sequences of different insect orders. The amino acid sequence of the cystine knot cytokine domain of TmSpz-like was used for the analysis. The .pim output files from ClustalX v. 2.1 were used to analyze the percentage sequence similarity of Spz-like among orthologous species. A phylogenetic tree was constructed based on the amino acid sequences of TmSpz-like using the neighbor-joining method with MEGA v. 7.0 [46]. The bootstrap consensus tree was inferred from 1000 replicates. The evolutionary distances were computed using the Poisson correction method. The amino acid sequence of Penaeus vannamei Spz5-like (PvSpz5-like; XP_027217999) was used as an outgroup for this analysis.

\subsection{Analysis of TmSpz-like Expression in Different Developmental Stages and Tissues}

Total RNA was isolated from different developmental stages (eggs, young instar larvae (tenth to twelfth instar larvae), late instar larvae (nineteenth to twentieth instar larvae), pre-pupae, 1-7-day-old pupae, and 1-5-day-old adults), as well as from different tissues (integument, hemocytes, gut, fat body, and Malpighian tubules dissected from both late instar larvae and 5-day-old adults; ovary and testis from 5-day-old adults) of T. molitor using the Clear-S total RNA extraction kit (Invirustech Co., Gwangju, South Korea), following the manufacturer's instructions. The isolated RNA $(2 \mu \mathrm{g})$ was reverse transcribed into complementary DNA (cDNA) using Oligo(dT) ${ }_{12-18}$ primer. The reverse transcription reactions were performed using a MyGenie96 Thermal Block (Bioneer, Korea) and AccuPower ${ }^{\circledR}$ RT PreMix (Bioneer, Korea), following the manufacturer's instructions under the following conditions: $72{ }^{\circ} \mathrm{C}$ for $5 \mathrm{~min}, 42^{\circ} \mathrm{C}$ for $1 \mathrm{~h}$, and $94{ }^{\circ} \mathrm{C}$ for $5 \mathrm{~min}$. cDNA was stored at $-20^{\circ} \mathrm{C}$ until analysis.

To investigate the effect of microbial infection on the expression of TmSpz-like, the twelfth to fifteenth instar larvae $(n=20)$ of T. molitor were infected with $1 \times 10^{6}$ cells $/ \mu \mathrm{L}$ of $E$. coli and S. aureus and $5 \times 10^{4}$ cells $/ \mu \mathrm{L}$ of $C$. albicans. The larvae belonging to the mock control group were injected with PBS. The whole larvae, hemocytes, gut, Malpighian tubules, and fat body were collected at 3, 6, 9, 12, and $24 \mathrm{~h}$ post-microbial inoculation. The relative expression level of TmSpz-like mRNA was investigated using qRT-PCR with AccuPower ${ }^{\circledR} 2$ Xreenstar ${ }^{\mathrm{TM}}$ qPCR Master Mix (Bioneer, Korea), synthesized cDNAs as templates, and TmSpz-like-specific primers designed using the Primer 3 plus program (http: //primer3plus.com/cgi-bin/dev/primer3plus.cgi) (TmSpz_qPCR_Fw and TmSpz qPCR_Rv) 
(Table 1). The PCR conditions were as follows: initial denaturation at $95^{\circ} \mathrm{C}$ for $5 \mathrm{~min}$, followed by 40 cycles of $95^{\circ} \mathrm{C}$ for $15 \mathrm{~s}$ (denaturation) and $60^{\circ} \mathrm{C}$ for $30 \mathrm{~s}$ (annealing and extension). qRTPCR analysis was performed using an AriaMx Real-Time PCR System (Agilent Technologies, Santa Clara, CA, USA), and the data were analyzed using AriaMx Real-Time PCR software. T. molitor ribosomal protein L27a-encoding gene (TmL27a) was used as an internal control. The mRNA expression levels were analyzed using the $2^{-\Delta \Delta C t}$ method [47]. The results are represented as mean \pm standard error from three biological replications.

\subsection{RNAi Analysis}

To synthesize the double-stranded (ds) RNA fragment of TmSpz-like, the TmSpz-like DNA fragment was PCR-amplified using gene-specific primers with a T7 promoter sequence at the $5^{\prime}$ end (Table 1). The primers were designed using the SnapDragon software (http: / / www.flyrnai.org/cgi-bin/RNAi_find_primers.pl) to prevent any cross-silencing effects. The fragments were amplified using AccuPower ${ }^{\circledR}$ Pfu PCR PreMix under the following conditions: initial denaturation step at $94{ }^{\circ} \mathrm{C}$ for $5 \mathrm{~min}$; followed by 35 cycles at $94{ }^{\circ} \mathrm{C}$ for $30 \mathrm{~s}$ (denaturation), $53{ }^{\circ} \mathrm{C}$ for $30 \mathrm{~s}$ (annealing), and $72{ }^{\circ} \mathrm{C}$ for $30 \mathrm{~s}$ (extension); and a final extension at $72{ }^{\circ} \mathrm{C}$ for $5 \mathrm{~min}$. The PCR products were purified using the AccuPrep PCR purification kit (Bioneer, Daejeon, Korea), while dsRNA was synthesized using the $\mathrm{EZ}^{\mathrm{TM}} \mathrm{T} 7$ high yield in vitro transcription kit (Enzynomics, Daejeon, Korea), following the manufacturer's instructions. The dsRNA product was purified through precipitation with $5 \mathrm{M}$ ammonium acetate and 99\% ethanol and quantified using an Epoch spectrophotometer (BioTek Instruments, Inc., VT, USA). The synthesized dsRNA was stored at $-20^{\circ} \mathrm{C}$ until analysis.

To validate the knockdown of TmSpz-like, $1 \mu \mathrm{g} / \mu \mathrm{L}$ of synthesized dsEGFP was injected into young instar larvae (tenth to twelfth instars; $n=30$ ) using disposable capillary needles mounted on a micro-applicator (Picospiritzer III Micro Dispense System; Parker Hannifin, $\mathrm{NH}$, USA). dsEGFP was used as a negative control.

\subsection{Effect of TmSpz-like Knockdown on Transcriptional Regulation of AMP and NF- $\kappa B$}

To further characterize the function of TmSpz-like in innate immunity, the effects of TmSpz-like knockdown on the expression levels of 15 T. molitor AMP-encoding and three NF- $\mathrm{B}$ transcription factor-encoding genes were examined after microbial challenge. TmSpz-like expression in larvae was knocked down using the RNAi technique. The TmSpzlike knockdown larvae were infected with E. coli, S. aureus, and C. albicans. The dsEGFP-and PBS-treated larvae served as the negative and injection controls, respectively. The larvae were homogenized at $6 \mathrm{~h}$ post-injection. Total RNA was extracted from the homogenized samples and subjected to cDNA synthesis as described above. The expression levels of 15 AMP genes (TmTenecin-1 (TmTene-1), TmTenecin-2 (TmTene-2), TmTenecin-3 (TmTene-3), TmTenecin-4 (TmTene-4), TmAttacin-1a (TmAtt-1a), TmAttacin-1b (TmAtt-1b), TmAttacin-2 (TmAtt-2), TmDefensin (TmDef), TmDefensin-like (TmDef-like), TmColeoptericin-A (TmColeA), TmColeoptericin-B (TmCole-B), TmColeoptericin-C (TmCole-C), TmCecropin-2 (TmCec-2), TmThaumatin-like protein-1 (TmTLP-1), and TmThaumatin-like protein-2 (TmTLP-2)) and three NF-kB factors involved in the Toll and IMD pathways (TmDorsal isoform X1 (TmDorX1), TmDorsal isoform X2 (TmDorX2), and TmRelish (TmRel)) were examined. The qRT-PCR analysis was performed using TmDorsal and TmRelish-specific primers (Table 1). All experiments were performed in triplicate.

\subsection{Statistical Analysis}

All experiments were performed in triplicate. The data were analyzed using one-way analysis of variance with SAS 9.4 software (SAS Institute, Inc., NC, USA). Cumulative viable rates were compared using Tukey's multiple range test. Differences were considered significant at $p<0.05$. The expression levels of the target genes were normalized with those of the internal control (TmL27a) and external control (PBS). The relative expression levels were calculated using the $2^{-(\Delta \Delta \mathrm{Ct})}$ method. 
Supplementary Materials: The following are available online at https:/ /www.mdpi.com/article/ 10.3390/ijms221910888/s1, Figure S1: Predicted model of TmSpz-like using the SWISS-MODEL program, Table S1: Percentage amino acid sequence identity of TmSpz-like with its orthologs in other insects.

Author Contributions: Conceptualization, Y.H.J. and Y.S.H.; methodology, Y.H.J. and Y.S.H.; software, Y.S.H.; validation, H.A.J., Y.H.J. and Y.S.H.; formal analysis, H.A.J. and Y.H.J.; investigation, H.A.J.; resources, Y.S.H.; data curation, H.A.J., M.A.M.K., B.B.K., Y.M.B. and K.B.P.; writing—original draft preparation, H.A.J. and B.B.P.; writing-review and editing, H.A.J., B.B.P., Y.S.L., Y.H.J. and Y.S.H.; visualization, H.A.J., Y.H.J. and Y.S.H.; supervision, Y.H.J. and Y.S.H.; project administration, Y.H.J. and Y.S.H.; funding acquisition, Y.S.H. All authors have read and agreed to the published version of the manuscript.

Funding: This research was supported by the Basic Science Research Program through the National Research Foundation of Korea (NRF) funded by the Ministry of Science, ICT and Future Planning (Grant No. 2018R1A2A2A05023367) and by the Korea Institute of Planning and Evaluation for Technology in Food, Agriculture, Forestry and Fisheries (IPET) through the Export Promotion Technology Development Program (Grant no. 617077-5), funded by the Ministry of Agriculture, Food, and Rural Affairs (MAFRA).

Institutional Review Board Statement: Not applicable.

Informed Consent Statement: Not applicable.

Data Availability Statement: Data is contained within the article or Supplementary Materials.

Conflicts of Interest: The authors declare no conflict of interest.

\section{References}

1. Lemaitre, B.; Hoffmann, J. The host defense of drosophila melanogaster. Annu. Rev. Immunol. 2007, 25, 697-743. [CrossRef] [PubMed]

2. Kim, C.H.; Kim, S.J.; Kan, H.; Kwon, H.M.; Roh, K.B.; Jiang, R.; Yang, Y.; Park, J.W.; Lee, H.H.; Ha, N.C.; et al. A three-step proteolytic cascade mediates the activation of the peptidoglycan-induced toll pathway in an insect. J. Biol. Chem. 2008, 283, 7599-7607. [CrossRef] [PubMed]

3. Roh, K.B.; Kim, C.H.; Lee, H.; Kwon, H.M.; Park, J.W.; Ryu, J.H.; Kurokawa, K.; Ha, N.C.; Lee, W.J.; Lemaitre, B.; et al. Proteolytic cascade for the activation of the insect toll pathway induced by the fungal cell wall component. J. Biol. Chem. 2009, 284, 19474-19481. [CrossRef] [PubMed]

4. Keshavarz, M.; Jo, Y.H.; Edosa, T.T.; Bae, Y.M.; Han, Y.S. Tmpgrp-sa regulates antimicrobial response to bacteria and fungi in the fat body and gut of tenebrio molitor. Int. J. Mol. Sci. 2020, 21, 2113. [CrossRef] [PubMed]

5. Edosa, T.T.; Jo, Y.H.; Keshavarz, M.; Kim, I.S.; Han, Y.S. Biosurfactants induce antimicrobial peptide production through the activation oftmspatzles intenebrio molitor. Int. J. Mol. Sci. 2020, 21, 6090. [CrossRef]

6. Yu, B.; Sang, Q.; Pan, G.; Li, C.; Zhou, Z. A toll-spatzle pathway in the immune response of bombyx mori. Insects 2020, 11, 586. [CrossRef]

7. Huang, X.; Xu, Y.; Zhang, Y.; Liu, J.; Luo, S.; Wu, J. Spatzle4 gene of silkworm, bombyx mori: Identification, immune response, and the effect of rna interference on the antimicrobial peptides' expression in the integument. Saudi J. Biol. Sci. 2018, 25, 1817-1825. [CrossRef]

8. Muhammad, A.; Habineza, P.; Wang, X.; Xiao, R.; Ji, T.; Hou, Y.; Shi, Z. Spatzle homolog-mediated toll-like pathway regulates innate immune responses to maintain the homeostasis of gut microbiota in the red palm weevil, rhynchophorus ferrugineus olivier (coleoptera: Dryophthoridae). Front. Microbiol. 2020, 11, 846. [CrossRef]

9. Edosa, T.T.; Jo, Y.H.; Keshavarz, M.; Bae, Y.M.; Kim, D.H.; Lee, Y.S.; Han, Y.S. Tmspz4 plays an important role in regulating the production of antimicrobial peptides in response to escherichia coli and candida albicans infections. Int. J. Mol. Sci. 2020, 21, 1878. [CrossRef]

10. Keshavarz, M.; Jo, Y.H.; Patnaik, B.B.; Park, K.B.; Ko, H.J.; Kim, C.E.; Edosa, T.T.; Lee, Y.S.; Han, Y.S. Tmrelish is required for regulating the antimicrobial responses to escherichia coli and staphylococcus aureus in tenebrio molitor. Sci. Rep. 2020, 10, 4258. [CrossRef]

11. Edosa, T.T.; Jo, Y.H.; Keshavarz, M.; Bae, Y.M.; Kim, D.H.; Lee, Y.S.; Han, Y.S. Tmspz6 is essential for regulating the immune response to escherichia coli and staphylococcus aureus infection in tenebrio molitor. Insects 2020, 11, 105. [CrossRef]

12. Nonaka, S.; Kawamura, K.; Hori, A.; Salim, E.; Fukushima, K.; Nakanishi, Y.; Kuraishi, T. Characterization of spz5 as a novel ligand for drosophila toll-1 receptor. Biochem. Biophys. Res. Commun. 2018, 506, 510-515. [CrossRef] [PubMed]

13. Chowdhury, M.; Li, C.F.; He, Z.; Lu, Y.Z.; Liu, X.S.; Wang, Y.F.; Ip, Y.T.; Strand, M.R.; Yu, X.Q. Toll family members bind multiple spatzle proteins and activate antimicrobial peptide gene expression in drosophila. J. Biol. Chem. 2019, 294, 10172-10181. [CrossRef]

14. Zhong, X.; Xu, X.X.; Yi, H.Y.; Lin, C.; Yu, X.Q. A toll-spatzle pathway in the tobacco hornworm, manduca sexta. Insect Biochem. Mol. Biol. 2012, 42, 514-524. [CrossRef] [PubMed]

15. Sun, Y.; Jiang, Y.R.; Wang, Y.; Li, X.S.; Yang, R.S.; Yu, Z.G.; Qin, L. The toll signaling pathway in the chinese oak silkworm, antheraea pernyi: Innate immune responses to different microorganisms. PLoS ONE 2016, 11, e0160200. [CrossRef]

16. Luna, C.; Wang, X.L.; Huang, Y.M.; Zhang, J.A.; Zheng, L.B. Characterization of four toll related genes during development and immune responses in anopheles gambiae. Insect Biochem. Mol. 2002, 32, 1171-1179. [CrossRef] 
17. Shin, S.W.; Bian, G.; Raikhel, A.S. A toll receptor and a cytokine, toll5a and spz1c, are involved in toll antifungal immune signaling in the mosquito aedes aegypti. J. Biol. Chem. 2006, 281, 39388-39395. [CrossRef] [PubMed]

18. Wang, P.H.; Liang, J.P.; Gu, Z.H.; Wan, D.H.; Weng, S.P.; Yu, X.Q.; He, J.G. Molecular cloning, characterization and expression analysis of two novel tolls (lvtoll2 and lvtoll3) and three putative spatzle-like toll ligands (lvspz1-3) from litopenaeus vannamei. Dev. Comp. Immunol. 2012, 36, 359-371. [CrossRef]

19. Yuan, K.; Yuan, F.H.; Weng, S.P.; He, J.G.; Chen, Y.H. Identification and functional characterization of a novel spatzle gene in litopenaeus vannamei. Dev. Comp. Immunol. 2017, 68, 46-57. [CrossRef]

20. Shi, X.Z.; Zhang, R.R.; Jia, Y.P.; Zhao, X.F.; Yu, X.Q.; Wang, J.X. Identification and molecular characterization of a spatzle-like protein from chinese shrimp (fenneropenaeus chinensis). Fish Shellf. Immunol. 2009, 27, 610-617. [CrossRef]

21. Jo, Y.H.; Kim, Y.J.; Park, K.B.; Seong, J.H.; Kim, S.G.; Park, S.; Noh, M.Y.; Lee, Y.S.; Han, Y.S. Tmcactin plays an important role in gram-negative and -positive bacterial infection by regulating expression of 7 amp genes in tenebrio molitor. Sci. Rep. 2017, 7, 46459. [CrossRef]

22. Jo, Y.H.; Patnaik, B.B.; Hwang, J.; Park, K.B.; Ko, H.J.; Kim, C.E.; Bae, Y.M.; Jung, W.J.; Lee, Y.S.; Han, Y.S. Regulation of the expression of nine antimicrobial peptide genes by tmimd confers resistance against gram-negative bacteria. Sci. Rep. 2019, 9, 10138. [CrossRef]

23. Ko, H.J.; Jo, Y.H.; Patnaik, B.B.; Park, K.B.; Kim, C.E.; Keshavarz, M.; Jang, H.A.; Lee, Y.S.; Han, Y.S. Ikkgamma/nemo is required to confer antimicrobial innate immune responses in the yellow mealworm, tenebrio molitor. Int. J. Mol. Sci. 2020, 21, 6734. [CrossRef]

24. Parker, J.S.; Mizuguchi, K.; Gay, N.J. A family of proteins related to spatzle, the toll receptor ligand, are encoded in the drosophila genome. Proteins 2001, 45, 71-80. [CrossRef]

25. Valanne, S.; Wang, J.H.; Ramet, M. The drosophila toll signaling pathway. J. Immunol. 2011, 186, 649-656. [CrossRef] [PubMed]

26. Parthier, C.; Stelter, M.; Ursel, C.; Fandrich, U.; Lilie, H.; Breithaupt, C.; Stubbs, M.T. Structure of the toll-spatzle complex, a molecular hub in drosophila development and innate immunity. Proc. Natl. Acad. Sci. USA 2014, 111, 6281-6286. [CrossRef]

27. Moussian, B.; Roth, S. Dorsoventral axis formation in the drosophila embryo-shaping and transducing a morphogen gradient. Curr. Biol. 2005, 15, R887-R899. [CrossRef] [PubMed]

28. Park, S.; Jo, Y.H.; Park, K.B.; Ko, H.J.; Kim, C.E.; Bae, Y.M.; Kim, B.; Jun, S.A.; Bang, I.S.; Lee, Y.S.; et al. Tmtoll-7 plays a crucial role in innate immune responses against gram-negative bacteria by regulating 5 amp genes in tenebrio molitor. Front. Immunol. 2019, 10, 310. [CrossRef]

29. Borst, D.W.; Bollenbacher, W.E.; O'Connor, J.D.; King, D.S.; Fristrom, J.W. Ecdysone levels during metamorphosis of drosophila melanogaster. Dev. Biol. 1974, 39, 308-316. [CrossRef]

30. Verma, P.; Tapadia, M.G. Immune response and anti-microbial peptides expression in malpighian tubules of drosophila melanogaster is under developmental regulation. PLoS ONE 2012, 7, e40714. [CrossRef]

31. Shukla, A.; Tapadia, M.G. Differential localization and processing of apoptotic proteins in malpighian tubules of drosophila during metamorphosis. Eur. J. Cell. Biol. 2011, 90, 72-80. [CrossRef]

32. Yu, Y.; Park, J.W.; Kwon, H.M.; Hwang, H.O.; Jang, I.H.; Masuda, A.; Kurokawa, K.; Nakayama, H.; Lee, W.J.; Dohmae, N.; et al. Diversity of innate immune recognition mechanism for bacterial polymeric meso-diaminopimelic acid-type peptidoglycan in insects. J. Biol. Chem. 2010, 285, 32937-32945. [CrossRef]

33. Sun, J.J.; Xu, S.; He, Z.H.; Shi, X.Z.; Zhao, X.F.; Wang, J.X. Activation of toll pathway is different between kuruma shrimp and drosophila. Front. Immunol. 2017, 8, 1151. [CrossRef]

34. An, C.J.; Jiang, H.B.; Kanost, M.R. Proteolytic activation and function of the cytokine spatzle in the innate immune response of a lepidopteran insect, manduca sexta. FEBS J. 2010, 277, 148-162. [CrossRef] [PubMed]

35. Bulet, P.; Cociancich, S.; Dimarcq, J.L.; Lambert, J.; Reichhart, J.M.; Hoffmann, D.; Hetru, C.; Hoffmann, J.A. Insect immunity. Isolation from a coleopteran insect of a novel inducible antibacterial peptide and of new members of the insect defensin family. $J$. Biol. Chem. 1991, 266, 24520-24525. [CrossRef]

36. Carlsson, A.; Nystrom, T.; de Cock, H.; Bennich, H. Attacin-An insect immune protein-binds lps and triggers the specific inhibition of bacterial outer-membrane protein synthesis. Microbiology 1998, 144 Pt 8, 2179-2188. [CrossRef] [PubMed]

37. Bechinger, B.; Lohner, K. Detergent-like actions of linear amphipathic cationic antimicrobial peptides. Biochim. Biophys. Acta 2006, 1758, 1529-1539. [CrossRef] [PubMed]

38. Ouyang, L.; Xu, X.X.; Freed, S.F.; Gao, Y.F.; Yu, J.; Wang, S.; Ju, W.Y.; Zhang, Y.Q.; Jin, F.L. Cecropins from plutella xylostella and their interaction with metarhizium anisopliae. PLoS ONE 2015, 10, e0142451. [CrossRef]

39. Ali Mohammadie Kojour, M.; Jang, H.A.; Edosa, T.T.; Keshavarz, M.; Kim, B.B.; Bae, Y.M.; Patnaik, B.B.; Han, Y.S.; Jo, Y.H. Identification, in silico characterization, and expression analysis of tenebrio molitor cecropin-2. Entomol. Res. 2021, 51, 74-82. [CrossRef]

40. Jang, H.A.; Park, K.B.; Kim, B.B.; Ali Mohammadie Kojour, M.; Bae, Y.M.; Baliarsingh, S.; Lee, Y.S.; Han, Y.S.; Jo, Y.H. Bacterial but not fungal challenge up-regulates the transcription of coleoptericin genes in tenebrio molitor. Entomol. Res. 2020, 50, 440-449. [CrossRef]

41. Iqbal, I.; Tripathi, R.K.; Wilkins, O.; Singh, J. Thaumatin-like protein (tlp) gene family in barley: Genome-wide exploration and expression analysis during germination. Genes 2020, 11, 1080. [CrossRef] [PubMed]

42. Maistrou, S.; Paris, V.; Jensen, A.B.; Rolff, J.; Meyling, N.V.; Zanchi, C. A constitutively expressed antifungal peptide protects tenebrio molitor during a natural infection by the entomopathogenic fungus beauveria bassiana. Dev. Comp. Immunol. 2018, 86, 26-33. [CrossRef] 
43. Zhang, R.; Zhu, Y.; Pang, X.; Xiao, X.; Zhang, R.; Cheng, G. Regulation of antimicrobial peptides in aedes aegypti aag2 cells. Front. Cell Infect. Microbiol. 2017, 7, 22. [CrossRef] [PubMed]

44. Keshavarz, M.; Jo, Y.H.; Park, K.B.; Ko, H.J.; Edosa, T.T.; Lee, Y.S.; Han, Y.S. Tmdorx2 positively regulates antimicrobial peptides in tenebrio molitor gut, fat body, and hemocytes in response to bacterial and fungal infection. Sci. Rep. 2019, 9, 16878. [CrossRef]

45. Larkin, M.A.; Blackshields, G.; Brown, N.P.; Chenna, R.; McGettigan, P.A.; McWilliam, H.; Valentin, F.; Wallace, I.M.; Wilm, A.; Lopez, R.; et al. Clustal w and clustal x version 2.0. Bioinformatics 2007, 23, 2947-2948. [CrossRef]

46. Kumar, S.; Stecher, G.; Tamura, K. Mega7: Molecular evolutionary genetics analysis version 7.0 for bigger datasets. Mol. Biol. Evol. 2016, 33, 1870-1874. [CrossRef]

47. Livak, K.J.; Schmittgen, T.D. Analysis of relative gene expression data using real-time quantitative pcr and the 2(t)(-delta delta c) method. Methods 2001, 25, 402-408. [CrossRef] [PubMed] 